\title{
CORRESPONDENCE
}

\section{AGAIN: HOW MANY MOVES TO THE RULE?}

\author{
C. Dane \\ 4208 Cantabury Lane \\ Jackson, Mich 49203-5165 \\ USA
}

[The Editors, in publishing this letter, do neither endorse nor oppose Mr. Dane's proposal, which is mainly being published because it exhibits the great variety of feasible $n$-move rules.]

I feel that the 50-move rule modifications as detailed on page 192 of the September, 1989 issue of the ICCA Journal should be changed as follows:

"The number of 50 moves mentioned in article 10.8 will be extended to

90 moves for the following positions:

(a) King and two Knights versus King and a Pawn

(b) King and Queen versus King and two Knights

(c) King and two Bishops versus King and a Knight

75 moves for the following positions:

(a) King, Queen and a Pawn one square from promotion versus King and Queen

(b) King, Rook, Pawn on a2 versus King, black Bishop, Pawn on a3 (and reflected positions)

100 moves for the following positions:

(a) King and Queen versus King and two Bishops

If the position of a King, Rook and Bishop vs. King and Rook is to be played, the position is to be adjudicated by an endgame database after 50 moves of play; the player with the Bishop (assumed to be White) gets a 50move extension if the following conditions are met:

(1) the position is a win;

(2) at least 30 of the previous 50 WTM positions were a win;

(3) White has made progress (in distance to mate), at least equal to the number of won positions in the previous 50 moves."

My proposed rules, I think, give sufficient leeway for less than optimal technique but conform to the spirit of the original race. 